\title{
Sobre espejos, simulacros y distorsiones: algunas consideraciones para leer Historia secreta de Costaguana (2007), de Juan Gabriel Vásquez ${ }^{1}$
}

\author{
Ricardo Carpio Franco ${ }^{2}$ \\ Universidad de Cartagena
}

\section{Resumen}

El presente ensayo aborda problemas relacionados con la configuración narrativa y discursiva de Historia secreta de Costaguana (2007), novela histórica del escritor colombiano Juan Gabriel Vásquez (1973). A la luz de conceptos como "nueva novela histórica" y "metaficción historiográfica", se aborda la búsqueda de las claves de una escritura en cuyo seno se debate la validez de los distintos discursos (historiográficos y ficcionales, centrales y periféricos, etc.) que pretenden dar cuenta de los hechos del pasado.

Palabras clave: narrativa colombiana, novela histórica, historia, discurso, metaficción historiográfica.

\begin{abstract}
This paper talks on topics related to the narrative and discursive settings of Historia secreta de Costaguana (2007) by Colombian writer Juan Gabriel Vásquez (1973). At light of concepts like "new historical novel" and "historiographic metafiction" and in the context of discussions on colonialism, this article speaks about the search for the keys to writing and discussion on validity of different discourses (historiographical and fictional, central and peripheral, etc.) and past events.
\end{abstract}

Key words: colombian narrative, historical novel, history, speech, historiographic metafiction.

\footnotetext{
${ }^{1}$ El presente texto hace parte de un trabajo más amplio titulado Espejos, simulacrosy distorsiones: hacia una tipología de la metaficción historiográfica en Historia secreta de Costaguana de Juan Gabriel Vásquez.

2 Profesional en Lingüística y Literatura de la Universidad de Cartagena. Autor del libro de cuentos Un buen lugar bajo la lluvia (Ediciones Pluma de Mompox, 2011). e-mail: ricardocarpiof@gmail.com
}

Recibido: Marzo, 2010 - Aprobado: Junio, 2010. 
Así, pues, lo que a continuación consigno no es lo que realmente sucedió, sino lo que parece verosímil que sucediera; no ofrezco hechos probados, sino conjeturas razonables.

Javier Cercas, Soldados de Salamina.

Si se nos dice que toda historia es ficción, los novelistas entendemos que la única forma de revelar el pasado es tratarlo como un producto narrativo, susceptible por lo tanto de ser recontado de cualquier forma. Mi Historia secreta de Costaguana cuenta la historia en clave de parodia o de farsa.

Juan Gabriel Vásquez, “El arte de la distorsión”.

“El arte de la distorsión”. Con este título apareció, en el número 76 de la revista El Malpensante, un artículo en que el escritor colombiano Juan Gabriel Vásquez ${ }^{3}$ propone y defiende la posibilidad de leer Cien años de soledad fuera de los parámetros del realismo mágico: como novela histórica, "como una visión distorsionada de la historia colombiana" (2007a: 19) ${ }^{4}$. Aunque la originalidad no sea el primer mérito de esta propuesta ${ }^{5}$, su importancia está en que nos permite ver cómo los nuevos autores crean sus obras a partir de la "mala interpretación" de su herencia literaria y, particularmente en el caso de las novelas históricas, de las verdades de la historia oficial. Es así como, según Vásquez, esa "mala lectura" está íntimamente ligada a los problemas que debió afrontar durante la concepción y el desarrollo

\footnotetext{
${ }^{3}$ Nacido en Bogotá (1973), Juan Gabriel Vásquez ha publicado, además de Historia secreta de Costaguana (2007), Los amantes de todos los santos (cuentos, 2001), El arte de la distorsión (ensayo, 2008) y Los informantes (2004).

${ }^{4}$ La idea general del artículo, y lo que parece un primer esbozo de la poética de la novela histórica en Vásquez, está muy bien expresado en estas líneas: "La historia como ficción: esta propuesta, que a finales de los años sesenta sumió a los historiadores en una crisis de la cual no han salido, ha tenido el efecto curioso de liberar por fin las posibilidades de la novela. Pues, como dice Byatt, "la idea de que la historia es ficción condujo a un nuevo interés en la ficción como historia'. Yo voy incluso más allá: la idea de que toda historia es ficción ha permitido a la ficción ganar una libertad inédita: la libertad de distorsionar la historia" (2007a: 22).

${ }^{5}$ Ya hace veinte años que Germán Espinosa se refería al carácter histórico que puede atribuirse a Cien años de soledad por su incursión en sucesos como la masacre de las Bananeras y las guerras civiles del siglo XIX. También la profesora norteamericana Lois Parkinson Zamora se refiere a la necesidad de "complicar" el concepto de "literatura histórica" para entender mejor las relaciones entre literatura e historia en autores como Borges, Fuentes, Cortázar, García Márquez y Vargas Llosa (2004: 13).
} 
de Historia secreta de Costaguana (2007), una novela histórica sobre el siglo XIX colombiano.

Bien recibido por autores como Mario Vargas Llosa, Enrique VilaMatas o John Banville, Juan Gabriel Vásquez hace parte de los escritores que, tras el Boom literario de la segunda mitad del siglo XX -y con el precedente común de una obra como la del chileno Roberto Bolaño-, han estado replanteando problemas relacionados con una escritura de lo latinoamericano desde Latinoamérica ${ }^{6}$. En medio de toda una literatura urbana, que en nuestro país ha sabido hallar sus mejores motivos en el narcotráfico (constituyendo lo que parece ser una nueva novela de la violencia), las dos que ha publicado Vásquez (ambas girando alrededor de hechos históricos) ${ }^{7}$ parecen volcar todo su interés hacia la búsqueda de ese momento difícil en que todo se vino abajo. Vásquez no es tanto un contador de muertos como un psicoanalista de la colectividad que rastrea la razón de nuestras perversiones y enfermedades nacionales en la infancia de lo que somos.

Historia secreta de Costaguana ofrece una mirada muy particular sobre el siglo que modeló la cara del país que hoy conocemos. Justo el día de la muerte de Joseph Conrad, el 7 de agosto de 1924, José Altamirano decide contarle a su "público lector" cómo su vida estuvo ligada a la del escritor polaco. En un gesto que nos obliga a pensar seriamente en el carácter de este hombre lenguaraz y sardónico, afirma que tiene pruebas suficientes para demostrar que Costaguana, la república suramericana erigida por Conrad a orillas del mar Caribe

\footnotetext{
${ }^{6}$ Además de Juan Gabriel Vásquez, otros nombres muy mencionados dentro de este nuevo canon son el de Jorge Volpi (México), Andrés Neuman (Argentina), Junot Díaz (República Dominicana), Santiago Roncagliolo (Perú), John Jairo Junieles (Colombia), etc. Aunque resulta inabarcable la cantidad de artículos y entrevistas en las que estos nuevos autores se cuestionan sobre su papel frente a la tradición y exponen las que consideran sus temáticas más recurrentes, es Jorge Volpi quien mejor sintetiza sus lugares comunes al declarar el fin de la literatura latinoamericana: "Después de Bolaño ya no existe nada que pudiéramos llamar literatura latinoamericana. Ninguno de los escritores posteriores a Bolaño está interesado en mostrar una especie de esencia latinoamericana particular (...) Son escritores con poéticas y obsesiones distintas, individuales, que no responden necesariamente a la antigua tradición latinoamericana y en donde hay muy pocos rasgos reconocibles". (Volpi, 2009a). El mismo Volpi afirma, sin embargo, que una constante en todos ellos es la "gran indiferencia ante la política y el compromiso" -obsesiones tan marcadas del Boom-, sin que eso haya medrado el interés por "algunos temas ligados a la realidad de nuestros países", como el narcotráfico y la violencia (Volpi, 2009b).

${ }^{7}$ El tema principal de Los informantes es la persecución que sufrieron muchos alemanes radicados en Colombia durante la Segunda Guerra Mundial.
} 
en Nostromo $(1904)^{8}$, es un simulacro ${ }^{9}$ creado con lo que él mismo le contó sobre los episodios más escabrosos que ocurrieron en Colombia desde los primeros años de su independencia). Así nos guía en su recorrido vital, siempre ante un panorama de inestabilidad política, de guerras civiles suscitadas por la ingenuidad o la mala intención, y de personajes cegados por el ansia de poder o el fanatismo: una Colombia que a finales del siglo XIX tuvo como saldo la reafirmación de ser enteramente libre para equivocarse a su antojo, con una autonomía política incapaz de evitar que, a conveniencia de los Estados Unidos de Norteamérica, el estado de Panamá reclamara su separación.

Nostromo es, entre otras cosas, una narración que contempla la historia latinoamericana desde un velero anclado en las aguas del Golfo Plácido. Costaguana viene a ser el resultado de ese mirar desde afuera: una imagen a calco de lo que un espectador europeo podría ver como el aborto de las ideas ilustradas en nuestro continente: repúblicas a medio hacerse, hombres desorientados por la incomprensión de su papel en "el concierto de las naciones civilizadas", pueblos que abrazan ciegamente las seducciones de la violencia. Concebida a expensas de ese mosaico prejuicioso de la vida latinoamericana, Historia secreta de Costaguana no puede ser más que un parásito sumamente lúcido, si se quiere. Esta afirmación, que en cualquier otro momento remitiría a un insulto, es sólo el señalamiento de una de las particularidades más evidentes de la novelística en la cual se inscribe la obra de Vásquez. En este momento parece más claro que nunca que las obras literarias encuentran su mayor riqueza de sentido en relación con otras obras, en el diálogo intertextual con su tradición ${ }^{10}$. Esa intertextualidad, presumible desde el instante en que el autor decide que su texto será una novela

\footnotetext{
${ }^{8}$ Nostromo es el título de la novela en que Joseph Conrad retrata los eventos políticos que terminaron por cercenarle a Costaguana una parte de su territorio. En este caso, el estado separatista se llama Sulaco y el asunto de fondo en la proclamación de su independencia es una mina de plata donde están implicados los intereses de un empresario norteamericano. También en esta novela está presente la intervención de "una potencia del norte", los ecos lejanos de guerras civiles interminables, los cambios bruscos de gobierno motivados por revoluciones de tipo militar, etc.

${ }^{9}$ Entendemos simulacro, en términos nietzscheanos, como "una representación sustantivada que compite ontológicamente con lo representado, lo sobrepuja, elimina y sustituye finalmente, para convertirse en el único ser objetivamente real" (Subirats, 2001: 75).

10 "Toda narración es -se sitúa- frente a otras narraciones y junto a ellas -es, por tanto, un 'escenario de intertextualidad'-y representa por este motivo un equilibrio entre movimientos contrarios: un movimiento de distanciamiento y otro de aproximación” (Rey Pereira, 2000: 39).
} 
histórica, se potencia cuando asumimos que Historia secreta de Costaguana nos remite también a la escritura de otra novela.

En la "Nota del autor", Vásquez explica cómo nació la idea de escribir Historia secreta de Costaguana. Mientras cumplía el encargo de preparar una biografía sobre Joseph Conrad, se encontró con un hecho que sorprendentemente no había tenido gran importancia para ningún novelista colombiano: en su juventud, viajando como grumete en el velero francés Saint-Antoine, el marinero polaco Józef Teodor Konrad Korzeniowski había estado en territorio colombiano después de pasar por Venezuela con rumbo al Golfo de México ${ }^{11}$. Es muy probable que avistara el puerto de Cartagena y que lo haya visitado. Aunque éste es uno de los periodos menos documentados en la vida de Conrad, algunos antecedentes sobre tráfico de armas con los rebeldes carlistas en España permitieron a Vásquez suponer como cierto (y aquí empieza ya su labor de novelista) que el SaintAntoine "estuviera contrabandeando armas para los conservadores colombianos, que por esos días intentaban echar abajo el gobierno liberal de Aquileo Parra" (2007c: 20). En este punto, Vásquez observa también que las revoluciones de Costaguana parecen fundarse en la percepción que tuvo Conrad de los enfrentamientos políticos colombianos y que, entre otras coincidencias, Sulaco corresponde bastante bien a Cartagena y don José Avellanos, gran pensador de la vida política de Costaguana, "debe mucho a Santiago Pérez Triana, hijo de Santiago Pérez, el liberal que había ocupado la presidencia de Colombia antes que Parra" (2007c: 21) ${ }^{12}$.

\footnotetext{
${ }^{11}$ En el cuento "Guayaquil", de Jorge Luis Borges, se dice lo siguiente: "Acaso no se puede hablar de aquella república del Caribe sin reflejar, siquiera de lejos, el estilo monumental de su historiador más famoso, el capitán José Korzeniowski" (citado en Vásquez, 2007b: 291). También García Márquez lo menciona en El amor en los tiempos del cólera: "durante una de las tantas guerras civiles del siglo anterior, Lorenzo Daza había sido intermediario entre el gobierno del presidente liberal Aquileo Parra y un tal Joseph K. Korzeniowski, polaco de origen, que estuvo demorado aquí varios meses en la tripulación del mercante Saint Antoine, de bandera francesa, tratando de definir un confuso negocio de armas. Korzeniowski, que más tarde se haría célebre en el mundo con el nombre de Joseph Conrad, hizo contacto no se sabía cómo con Lorenzo Daza, quien le compró el cargamento de armas por cuenta del gobierno, con sus credenciales y sus recibos en regla, y pagado en oro de ley. Según la versión del periódico, Lorenzo Daza dio por desaparecidas las armas en un asalto improbable, y las volvió a vender por el doble de su precio real a los conservadores en guerra contra el gobierno" (García Márquez, 1985: 435).

${ }^{12}$ En una breve nota biográfica, y laudatoria, sobre Pérez Triana, Baldomero Sanín Cano recuerda, entre otras empresas editoriales del "eminente hombre", la revista Hispania, que fue publicada en Londres desde 1910 con la "simpatía y el apoyo" de Cunninghame Graham, conocido amigo de Conrad (Pérez Triana, 1972: 24).
} 
Es así como José Altamirano, en un ataque de paranoia contrario a toda la prudencia "necesaria" para afrontar los mecanismos de la ficción, acusa a Conrad de haberse robado su historia y la de su país. Pese a lo poco confiable que pueda parecernos quien se exprese en estos términos, Altamirano consigue su objetivo, que es exactamente el mismo del tipo de novela que estudiaremos: sembrar la duda en medio de las verdades mejor cultivadas de la historia oficial. Después de Historia secreta de Costaguana resulta casi imposible leer Nostromo sin pensar en las coincidencias entre su trasfondo político y social y el que ofrecía la Colombia de la segunda mitad del siglo $\mathrm{XIX}^{13}$. Podemos anticipar, a partir de esto, que lo que se encuentra en el centro de gravitación de Historia secreta de Costaguana no es tanto la historia de Colombia como la de Conrad, y que, en todo caso, su propósito de fondo no es presentar una biografía malintencionada del escritor polaco, sino revisar el proceso de transgresión de la realidad que lleva a cabo en la escritura de Nostromo. Ésta podría ser, dentro de la tradición nacional del género ${ }^{14}$, la obra que va más lejos en la ruptura de los principios que habitualmente han permitido reconocer si una novela es histórica, a saber: la recreación de unos acontecimientos pertenecientes al pasado histórico, su grado de "referencia" a los documentos que registran ese pasado ${ }^{15}$. La voz de Altamirano, que previene constantemente a los "lectores del jurado" sobre su autonomía de narrador, constituye una nota obsesiva sobre la evidencia de que la relación entre historia y novela es una relación

\footnotetext{
${ }^{13}$ Malcolm Deas, cuyo artículo cita Vásquez en la nota al lector que hemos mencionado, enumera varios eventos y circunstancias de la historia colombiana presentes en la novela de Conrad (2006: 271-284).

${ }^{14}$ No nos adentraremos en este punto por considerar que en la evolución de la novela histórica colombiana no se presenta un hito particular dentro del proceso de transformaciones que ha sufrido el género en Latinoamérica. Pese a que Ingermina, o la hija de Calamar (1844), de Juan José Nieto, es considerada la primera novela histórica de la tradición latinoamericana, en general no puede hablarse de un papel mayor de los escritores colombianos durante el periodo de más de un siglo que ha transcurrido hasta la publicación de La tejedora de coronas (Espinosa, 1986) o El general en su laberinto (García Márquez, 1989), o los buenos logros en que poco más tarde se constituyen, por ejemplo, La ceiba de la memoria (Burgos Cantor, 2007) o la trilogía en curso de William Ospina sobre el descubrimiento de América. Para ampliar el tema de la novela histórica en América Latina, véase Franco (1990) y Pons (1996). Para la novela histórica en Colombia, McGrady (1960), Curcio Altamar (1957) y Melo (1988).

15 "El tema de la referencialidad sigue siendo el eje alrededor del cual gira la mayor parte de las consideraciones que la crítica hace sobre la novela histórica, bien sea para referirse al apego de una obra a la documentación o a la verosimilitud, bien para hacer notar el alejamiento de estos referentes. En ambos casos, el género se mide en buena medida en relación con la referencia, quizás porque lo temático, el contenido, ha sido la base de la definición del género" (Pulido Herráez, 2006: 203).
} 
textual, una confrontación de escrituras. En esta forma de asumir el problema del referente es donde mejor se evidencia, según Fernández Prieto, que el propósito del novelista ha pasado de la recreación de unos acontecimientos históricos a la reflexión "acerca de la verdad histórica y la forma de construirla” (1995: 215). En otras palabras de la autora: "el interés por saber qué pasó se ha desplazado hacia el quién y cómo lo contó, y hacia el quién y el cómo lo lee y lo interpreta" (1995: 214). Este cambio de perspectiva, sin embargo, no es el resultado de ningún manifiesto sino de un proceso evolutivo cuyo inicio podemos rastrear en Europa a finales del siglo XVIII.

\section{Un primer acercamiento a los problemas teóricos de la novela histórica}

Durante casi dos siglos la novela histórica ha estado permanentemente en el centro de todo tipo de discusiones críticas: desde su vinculación con las corrientes literarias e historiográficas dominantes en Europa durante el siglo XIX hasta las nuevas posibilidades que le abrieron las vanguardias del siglo XX, desde la polémica sobre su legitimidad como medio para representar la verdad histórica hasta el reconocimiento de su papel activo en la erosión de las grandes narrativas modernas, etc. A continuación presentamos brevemente algunos aspectos teóricos relacionados con la evolución de este género novelístico y los problemas conceptuales que dificultan cualquier intento de definirla.

\subsection{La novela histórica: un problema de definición}

Si bien es cierto que en los últimos años se ha radicalizado la postura de quienes asumen una actitud revisionista frente a los relatos de la historia oficial ${ }^{16}$, no es nada reciente la discusión sobre las verdaderas posibilidades de la novela histórica en cuanto a la escritura del pasado. Esta cuestión está ligada, inevitablemente, al problema de su definición genérica, que es, entre otras cosas, el problema ofrecido por la hibridez de su carácter. Cada vez que consideramos la existencia de una escritura que se atreve a reunir en un solo texto las pretensiones tan aparentemente "opuestas" del género histórico -como interpretación científica de los hechos ocurridos en el pasadoy el literario -como creador de realidades ficcionales-, se vuelve inevitable enfrentarse a las siguientes preguntas: ¿Qué es la historia? ¿Un hecho histórico es necesariamente un hecho real, o viceversa?

${ }^{16} \mathrm{El}$ afán de revisar los relatos históricos oficiales y, en general, cualquier producto de los discursos hegemónicos es, precisamente, el principal rasgo de la escritura posmoderna (Grützmacher, 2006: 150). 
¿Qué presupuestos son los que dan licencia para "ficcionalizar" la historia? ¿Qué clase de conocimiento se genera a partir de ese proceso de hibridación que resulta de dar un tratamiento ficcional a los sucesos históricos? ${ }^{17}$ Dado que el género se ha consolidado, a pesar de la contradicción que implica, entonces ¿en qué consiste una "nueva clave" para entender los problemas que plantea la historia en cuanto se le asume como tema literario? ¿Cuáles son los lineamientos que orientan una escritura cuya más alta pretensión es iluminar el pasado desde la conciencia de una libertad creadora que da "derecho a modificar las cronologías, cambiar los escenarios, destruir las causalidades" (Vásquez, 2007ạ: 21)?

Intentar darle una respuesta a estos interrogantes nos sitúa inmediatamente frente a varias circunstancias cruciales que tienen que ver con la tradición del género de la novela histórica: 1) la relación que se plantea en su interior entre literatura e historia, 2) la evolución del género en tanto se acoge a la evolución que -cada uno por su parte o en constante interrelación- han mostrado la novela y los paradigmas historiográficos; y, más concretamente, en lo que concierne al presente trabajo, 3) cómo determinan estas consideraciones teóricas la configuración de una novela como Historia secreta de Costaguana. En primer lugar, tendríamos que detenernos frente al principal rasgo de la novela histórica: el carácter híbrido que le otorga la combinación interna de dos discursos que, al menos por sus pretensiones de verdad, se mantienen permanentemente divorciados $^{18}$. Aunque la historia y la novela se han mantenido en

17 "La novela -opina Vásquez- es una herramienta de conocimiento. Al contrario de otros medios de conocimiento, como la historiografía, el documental, el ensayo, la novela no refleja la realidad sino que añade algo a la realidad. La única obligación de la novela que trata sobre la historia es no ser redundante" (Friera, 2009). Hayden White, refiriéndose a la estructura "precrítica" de las obras históricas, en la que se conjuga una serie de decisiones compositivas de carácter netamente lingüístico, alude también al hecho de que la narratividad, en tanto forma necesaria para la organización causal de los acontecimientos, enfrenta al historiador a los mismos problemas poéticos del escritor de ficciones: "la misma distinción entre acontecimientos reales e imaginarios, básica en las formulaciones modernas tanto de la historia como de la ficción, presupone una noción de realidad en la que se identifica 'lo verdadero' con 'lo real' sólo en la medida en que puede mostrarse que el texto de que se trata tenga carácter de narratividad" (1992: 22).

${ }^{18}$ En el libro que ha dedicado a exponer los principales puntos teóricos de la "nueva historia", Miguel Ángel Cabrera nos ofrece la siguiente definición de "discurso": "un discurso es una estructura específica de sentencias, términos y categorías, histórica, social e institucionalmente establecida, que opera como un auténtico sistema constituyente de significados mediante el cual los significados son construidos" (2001: $52)$. 
estrecha relación, siempre con ese algo de intercambio conflictivo ${ }^{19}$, sólo hasta principios del siglo XIX se configura por fin lo que hoy conocemos como novela histórica. Pocos críticos están en desacuerdo con Georg Lukács cuando afirma que fue Walter Scott quien concibió por primera vez la posibilidad de recuperar en una novela, y bajo una visión esmeradamente antropológica, los hechos del pasado ${ }^{20}$. A pesar de que en siglos anteriores se había generado una literatura con historias ambientadas en lugares y tiempos lejanos ${ }^{21}$, "el gran cumplimiento ampliador de las formas épicas modernas ha sido obra de Walter Scott, con su unión de una forma épica cerrada, total, y la historicidad y socialidad conscientes del contenido, tanto en el todo como en los detalles" (Lukács, 1976: 2). Después de ese primer momento puede señalarse una evolución, ya definitivamente bajo la vivencia de "lo histórico-social en el destino de cada individuo" (3), que ha ido complicando los alcances de la novela histórica.

Al presente, incluso podemos afirmar que cualquier búsqueda de una definición de novela histórica ha de acatar el momento en que nos preguntamos por ella, "en cuanto que tenemos que ajustar el concepto de novela histórica a la evolución de la novela, a la tradición y producción literaria que siguió a la definición original del género y al cambio mismo del concepto de historia" (Pons, 1996: 35). A fin de cuentas, la tradición de la novela histórica está hecha de la conciencia que, al momento de la escritura ${ }^{22}$, han tenido los autores sobre la relación entre literatura e historia que se sustenta su mundo ficticio.

\footnotetext{
${ }^{19}$ Pudiera pensarse incluso en el carácter histórico de las obras de Homero o la recursividad literaria presente en los libros de Heródoto.

${ }^{20}$ Pons cita el libro de Elizabeth Wesseling (Writing history as a prophet. Posmodernist innovations of the historical novel, 1991), "uno de los estudios más recientes de la novela histórica", como una de las posturas mejor argumentadas en contra de la afirmación de Lukács: "Las novelas históricas propias, dice Wesseling, emergieron hacia finales del siglo XVIII, cuando los novelistas comenzaron a utilizar información recogida por los anticuarios respecto de las costumbres, hábitos, vestimenta y la arquitectura de previas eras con el objeto de situar, en un detallado contexto histórico, las aventuras de personajes predominantemente ficticios". No obstante, Pons vuelve a resaltar lo que parece el mayor acierto de Lukács: la consideración de que "lo que les hace falta a las novelas producidas antes de Scott es precisamente lo específicamente histórico, es decir, la capacidad de derivar la individualidad de los personajes de la peculiaridad histórica de sus épocas" (Pons, 1996: 74).

${ }^{21}$ En todo caso, el pasado aparece como mero elemento decorador. Algo de eso se podía ver todavía en Alejandro Dumas, escritor contemporáneo de Scott, y, en general, en las novelas que no persiguen o no alcanzan el propósito de re-construir el pasado, característica de las novelas históricas descritas por Lukács. Para Dumas, "la historia es tan sólo un clavo del cual pende el cuadro" (citado en Aguirre, 2001: 170).

${ }^{22}$ Respecto a la "parcialidad introducida por el sujeto" que escribe la historia, podemos decir con palabras cercanas a Hegel que "se escribe desde el presente lo que el mismo presente posibilita" (Rey Pereira, 2000: 32).
} 
Pero, ¿a qué nos referimos cuando hablamos de un vínculo entre literatura e historia? ¿Es acaso una relación directa entre "lo ficticio" y "lo real", o un cruce entre dos formas de concebir y escribir el mundo, de representarlo? ¿Es suficiente que una novela incluya información sobre un pasado verificable para que la podamos considerar como histórica, o debe cumplir con algunos requisitos estructurales y compositivos que le permitan ser catalogada como tal?

Para María Cristina Pons este es uno de los puntos más resbaladizos en que se encuentra quien pretenda dar alguna definición del género. El riesgo, según ella, está en atreverse a afirmar que la novela histórica es aquella que incluye situaciones y personajes históricos en su argumento. Éste resulta un criterio demasiado ambiguo, que daría derecho a sostener que cualquier novela es histórica, al menos en cuanto refleja ciertos rasgos de la época en que fue escrita ${ }^{23}$. Precisamente aquí se acusa el señalamiento que hace Lukács en el sentido de que a las ficciones anteriores a Scott no les basta el material histórico presente en sus argumentos para constituirse en novelas históricas, sino que lo que da tal calidad a las de Scott es su esfuerzo por reconstruir una época perteneciente al pasado: por "producir un reflejo artístico de la historia"24. Un requisito fundamental al momento de clasificar las novelas históricas es, entonces, el claro propósito de re-construir, desde la ficción, un momento histórico concreto ${ }^{25}$.

\footnotetext{
${ }^{23}$ El asunto del segmento de historia del que se ocupa la novela sigue siendo un punto crítico para la definición del género. No sólo porque nos enfrenta a preguntas esenciales sobre la naturaleza misma de la historia, sino porque resulta arriesgado atreverse a decidir a qué punto del pasado debe referirse una novela para ser considerada histórica o qué tanta distancia debe mediar entre los escritores y el periodo histórico que están novelando. ¿Hay realmente un buen argumento para excluir de la categoría de novela histórica a la novela testimonial, política o de dictador?

${ }^{24}$ Aunque Lukács advierte con mucha prudencia sobre la "historicidad" del género, en el sentido de que está sujeto a los cambios del presente desde el cual se escribe, Pons señala, entre los limitantes de su acercamiento a la novela histórica, su consideración de la novela de Scott como el baremo más elevado para medir el género: de ahí que excluya aquellas que se refieren a un pasado demasiado distante, sin posibilidad de ser referenciado como una "precondición directa del presente", o las que no tienen por héroe a "un personaje de la época, mediocre y pasivo". En fin, a las que no se rijan por "los parámetros de la novela histórica clásica" (Lukács, 1996: 48-51).

${ }^{25}$ Como en el caso de los textos históricos, es un factor pragmático el que da su carácter a la novela histórica: la intencionalidad. Es en esta instancia donde los metatextos (las enunciaciones que, intercalándose en el discurso narrativo, nos hablan sobre el tipo de texto que estamos leyendo) entran a desempeñar un papel importante como evidencias de la posición que el autor, o su narrador, asume frente a la escritura de la historia. Coincidiendo con esta afirmación, Rey Pereira señala que, dado el impedimento de evadir su propia subjetividad, al novelista y al historiador sólo los diferencia la intención con que asumen la escritura del pasado. Mientras el historiador presenta su trabajo "como una labor de reconstrucción que aspira a ser calificada de verídica", el novelista "genera una realidad que intencionadamente contiene elementos inexistentes en la realidad empírica" (2000: 28-29).
} 
Sin embargo, como veremos enseguida, el propósito de la novela histórica contemporánea es diametralmente opuesto al modelo ideal descrito por el filósofo ruso. Se conserva intacta la conciencia de que se está afrontando el pasado histórico desde la ficción, pero lo que se decide hacer con él no es simplemente reconstruirlo a través del arte, sino indagarlo abiertamente, de-construirlo para volver a armarlo como un juego de espejos y simulacros ${ }^{26}$. Resulta tentador el riesgo de afirmar que la novela histórica actual ha vuelto a las "niñerías" de las novelas anteriores a Walter Scott, pero esta vez como una vieja totalmente amargada por el falseamiento de sus viejas verdades. El suyo es un juego en el que ya no es posible la inocencia.

El problema para cualquier definición del género residiría entonces en ignorar esta conciencia de que se están manipulando unos sucesos del pasado a través de los medios de representación que ofrece la novela. Pons es clara al afirmar que, aunque "definitoria", dicha incursión en los hechos históricos "no es privativa" de la novela histórica, que comparte su objeto no sólo con la historia, sino también con otros géneros narrativos como el testimonio, la biografía, el reportaje histórico, la historia novelada. En consecuencia, "la novela histórica es [sólo] una manera particular de incorporar la historia en la ficción" (Pons, 1996: 35). Y a partir de ahí se define como género en la medida en que éstos "tienen métodos y medios de percibir, conceptualizar y evaluar una realidad; son portadores de un contenido ideológico, y proveedores de una forma y un 'lenguaje' que expresan una determinada actitud hacia la realidad" $(17)^{27}$. Lo siguiente es preguntarnos por los métodos y medios de que se sirve el autor para configurar la narración de Historia secreta de Costaguana. ¿Cuál es el contenido ideológico que revela ese tono resentido y burlón con que José Altamirano habla siempre de la historia de su país, de la vida de Joseph Conrad y de su propia vida? ¿Qué actitud ante la realidad revela una escritura que se atreve a desvirtuarla sin más, a dar de ella una versión que atenta flagrantemente contra el conocimiento del pasado que se transmite en los manuales?

\footnotetext{
${ }^{26}$ Aludimos con esto a la creación novelística de una imagen o versión del mundo (presentada luego como su fiel reflejo) a través de la confrontación de discursos y narrativas históricos con discursos y narrativas ficcionales.

${ }^{27}$ Barthes irá aún más lejos al resaltar el compromiso histórico de quien decide pronunciarse: "el lenguaje nunca es inocente". Según su juicio, la escritura implica "la reflexión del escritor sobre el uso social de su forma y la elección que asume (...) la escritura es por lo tanto esencialmente la moral de la forma". Y continúa enseguida: "De esta manera, la elección, y luego la responsabilidad de una escritura, designan una libertad, pero esta libertad no tiene los mismos límites en los diferentes momentos de la Historia. Bajo la presión de la Historia y de la Tradición se establecen las posibles escrituras de un escritor dado: hay una Historia de la Escritura" (Barthes, 2005: 23-24)
} 
"Una manera particular de incorporar la historia en la ficción" o, como dirá más adelante, "un modo particular de ficcionalización de la historia" (71). Este es tal vez el mejor punto de partida tanto para una búsqueda de sentido en la posibilidad de definir el género de la novela histórica, como para seguir los avatares de su evolución. Por una parte, nos pone frente a la circunstancia de que la novela histórica está enmarcada en un conjunto de escrituras que se acercan a los sucesos del pasado desde una perspectiva propia. Es decir, que desde su posición guarda con otros géneros una distancia sustentada por una idea de lo que son la novela y la historia y la posibilidad expresiva que nace de su unión. Esta misma confrontación frente a otros géneros es la que se produce entre novelas históricas de épocas distintas: si se mira desde el punto de vista de la poética, nos damos cuenta enseguida cómo ha variado con el tiempo la idea de lo que debe ser una novela histórica, ya sea que se la conciba desde una estética romántica o realista, ya sea apegada al naturalismo de finales del siglo XIX o a las corrientes de vanguardia que se habían madurado a principios del siglo XX; ya sea desde un compromiso abierto con los valores de la modernidad o desde las rupturas más profundas a que ha llegado la visión posmoderna del mundo.

Lo anterior se explica muy bien si tenemos en cuenta que uno de los criterios para definir el carácter histórico de una novela está dado por la manifestación explícita del propósito que tiene el narrador de reescribir unos sucesos históricos. Al principio citábamos a Parkinson Zamora para referirnos a la necesidad de "complicar" el concepto de literatura histórica en su relación con obras que generalmente no son consideradas como tales. Uno de los argumentos de esta autora es que aunque esos escritores (Borges, García Márquez, Cisneros, etc.) suelen tomar como base de sus obras "las historias registradas de las naciones y los individuos (...), no siempre lo hacen en forma explícita" (Parnkinson Zamora, 2004: 13). El carácter histórico de estas obras estaría, como lo está implícitamente en todas las actividades humanas, en que pertenecen a una encrucijada temporal y son, por tanto, reflejo de ciertas formas históricas de sentir y entender el mundo. Esta afirmación consigue ampliar el concepto de "literatura histórica", incluyendo en él a todas aquellas novelas o relatos que de una u otra manera se refieran a temas históricos (entre ellos el presente) ${ }^{28}$, pero a la vez restringe el marco de las novelas históricas en tanto género específico. Nos permite definirlas en términos de la intención explícita de narrar unos hechos del pasado histórico desde la ficción.

${ }^{28}$ No está de sobra aclarar que, al menos para lo que nos toca, "historia", además de referirse a los "relatos historiográficos", es sinónimo de "pasado histórico". 
Es así como, más allá de la variabilidad que cada época registra en el tratamiento de los temas históricos, está presente un eje central a partir del cual se desprenden todas las consideraciones teóricas y las realizaciones novelísticas propiamente dichas: esto es, que en la novela histórica "la acción y los personajes se sitúan en un periodo del pasado histórico", que "ese pasado no es legendario o fantástico, sino concreto, datado y reconocible" (Fernández Prieto, 1995: 213). A partir de ahí se verán distintas consideraciones sobre la distancia que debe mediar entre autor y el momento histórico del que nos habla, sobre la fidelidad de la novela a los documentos y la pertinencia de clasificarla de acuerdo a su "referencialidad". En fin, sobre los motivos que justifican, por ejemplo, el protagonismo en la acción novelesca de personajes centrales de la historia o la calificación histórica de una novela como Cien años de soledad.

En este caso no intentaremos dar una definición totalizadora de la novela histórica (además de ser imposible, porque iría en contra de uno de los supuestos más valiosos del tipo de novela que estamos estudiando: la imposibilidad de una escritura total). Sólo nos propondremos analizar y comprender los distintos elementos que configuran la narración en la novela de Juan Gabriel Vásquez (esto, sin embargo, no supone negar la eventualidad de referirnos a unos preceptos genéricos que ayuden a establecer un contrato de lectura).

\subsection{Novela histórica de finales del siglo XX y "nueva historia"}

Una vez que hemos revisado los problemas centrales para la definición de la novela histórica, tenemos que volver al punto crucial que representa su objeto de conocimiento. Para Celia Fernández Prieto, ese "pasado reconocible" del cual se ocupa la novela es un "tiempo que ha quedado fijado en documentos escritos, que ha dejado sus huellas en la realidad (ruinas, monumentos, obras de arte, objetos, etc.), y cuya existencia está avalada por la historiografía” (1995: 213). Se trata de un pasado al que sólo se puede acceder a través de las versiones que previamente ofrecen los documentos de archivo y las obras historiográficas o novelísticas que lo han abordado. De ahí que la novela histórica esté tan estrechamente ligada a los paradigmas que guían dichas interpretaciones. Esa novela histórica clásica, que debía ser capaz de hacernos reexperimentar la realidad social y económica de la época a que se hace referencia, se solventaba en la confianza de poder "lograr un conocimiento objetivo del pasado", con "la narración como discurso transparente y apto para transmitir la verdad de lo que realmente ocurrió" (214). Aunque esa confianza había empezado a desvanecerse con la "crisis del historicismo" (que, hacia finales del 
siglo XIX, propiciaron novelistas como Tolstoi y filósofos de la talla de Nietzsche y Schopenhauer), en las últimas décadas del siglo XX "ha quedado completamente resquebrajada debido en gran parte a las corrientes post-estructuralistas que subrayaron la capacidad del lenguaje (y de la narración) no para reproducir sino para construir la realidad" (214).

Pero, como decíamos hace un momento, no sólo se trata de un conflicto abierto entre lo que la historia y la novela pretenden del pasado, sino de la complementación que se lleva a cabo entre los paradigmas historiográficos y la escritura novelística. Esta ruptura con respecto a la confianza en la posibilidad de un conocimiento objetivo por parte de la historia, y con la idea de poder reconstruir fielmente, a través de una ficción, las dinámicas económicas y sociales de un determinado momento del pasado, viene de la mano con un proceso de cambio al interior de la propia disciplina historiográfica (Cabrera, 2001: 21). Un claro ejemplo de ello es el giro que se registra al interior del relato histórico cuando el narrador omnisciente de las novelas románticas y realistas empieza a ser desplazado por la voz de alguien que habla desde una posición peligrosamente cercana a los hechos que cuenta: el paso de un narrador que mira desde arriba, que todo lo ve y todo lo sabe, a uno que, por ser parte del desorden de los acontecimientos, se enfrenta a la incertidumbre y la vacilación de una perspectiva que sólo le permite entender parcialmente lo que sucede a su alrededor. "La elección de este tipo de narradores -apunta Fernández Prietose relaciona con la crisis de la historiografía, el replanteamiento del concepto de verdad en la epistemología contemporánea y la imposibilidad de separar el relato histórico de los presupuestos culturales e ideológicos del historiador" (1996: 107).

En los años veinte del siglo pasado, el materialismo histórico y la Escuela de Annales emprendieron la reorientación disciplinar hacia la "historia social" mediante "el paulatino abandono de la política institucional como objeto primordial de estudio y el desplazamiento del interés analítico hacia los fenómenos sociales y económicos" (Cabrera, 2001:21). Se pasó de una historia de los grandes personajes, protagonistas de los acontecimientos que han marcado los hitos de la civilización occidental, hacia una historia de las estructuras económicas y políticas. "La premisa teórica básica de la historia social es que la esfera socioeconómica constituye una estructura objetiva, en el doble sentido de que posee una autonomía irreductible y está dotada de un mecanismo interno de funcionamiento y de cambio y de que es portadora de significados intrínsecos" (Cabrera, 2001: 22). Según esto, el comportamiento de los individuos y los fenómenos de 
la cultura se explican como simples reflejos de lo que ocurre a nivel de la superestructura económica y social.

El panorama historiográfico estuvo más o menos estable, repartido entre la "historia tradicional" y la historia social, hasta las décadas de 1960 y 1970, cuando empezó la revisión del modelo explicativo de la historia social y fue cobrando mayor interés el estudio de la cultura como factor activo y determinante en la "producción de sentido" dentro de la estructura social. Según Cabrera, "fue el 'desencanto' con la explicación de todo en términos económicos y sociales lo que impulsó a numerosos historiadores a reconsiderar la naturaleza y el papel de la cultura, entendida como repertorio de mecanismos interpretativos y sistema de valores de la sociedad" (2001: 24). El resultado de todo esto fue una teoría de la sociedad que se basa "en la interacción entre atributos materiales y propiedades simbólicas, entre la presión de la realidad y la capacidad generativa de la cultura, entre coacción externa e iniciativa individual", para dar cuenta del funcionamiento y del cambio de las sociedades humanas ${ }^{29}$.

Sólo hasta los años noventa, sin embargo, vino a consolidarse plenamente "la nueva historia" ${ }^{30}$, el resultado más notorio en este proceso de reorientación de los estudios historiográficos. Cabrera insiste en que el primer rasgo y factor desencadenante de esta evolución ha sido la conciencia cada vez más clara entre los historiadores de la crisis experimentada por el concepto de realidad objetiva: la "puesta en cuestión de la premisa de que las sociedades humanas están compuestas por una esfera objetiva (identificada, de manera general, con la instancia socioeconómica), que ostenta la primacía causal, y por una esfera subjetiva o cultural,

${ }^{29}$ Manifestación de esta forma de abordar los fenómenos de la cultura es, por ejemplo, la aparición de la microhistoria o la historia de la vida cotidiana (Cabrera, 2001: 27-8).

${ }^{30}$ Entre otras, pudiéramos enumerar las siguientes como las propuestas más relevantes de la "nueva historia": "el cuestionamiento de las explicaciones deterministas y la decantación hacia análisis particularizados [...], el desplazamiento de la historia política por la de las mentalidades, por la exploración de las representaciones del imaginario colectivo [...], la extensión del campo de la historia a la vida cotidiana, la visión del campo de los acontecimientos determinantes no tanto desde el centro y desde arriba como desde la periferia y desde abajo [...], el descrédito de una Historia basada en las intenciones y estrategias conscientes de sus protagonistas y la apertura hacia una historia que se hace cargo de la complejidad de las circunstancias, del entrecruzamiento de fuerzas heterogéneas, incluso de la relevancia de los factores inconscientes [...], la puesta entre paréntesis de la supremacía del documento y de su supuesta objetividad [...], una creciente interdisciplinariedad [...], el cese de la confianza en un modelo de historia a la vez trascendente, universal y objetiva, y su progresiva sustitución por una forma de trabajar consciente de la propia relatividad, de los límites y los intereses propios, réplica a Hegel” (Oleza Simó, 1995: 84). 
que deriva de aquella, y de que, por consiguiente, la conciencia y las acciones de los individuos están determinadas causalmente por sus condiciones sociales de existencia" (2001: 13). Señala, así mismo, que la razón fundamental para poner en duda el carácter objetivo de la realidad social es que el propio análisis histórico confirma que "dicha realidad no se incorpora nunca por sí misma a la conciencia, sino que lo hace siempre a través de su conceptualización" $(48)^{31}$. Este será un concepto definitivo para entender a qué nos estamos refiriendo cuando hablamos de una interacción entre los paradigmas historiográficos y la escritura de las novelas históricas ${ }^{32}$.

\section{3. "Nueva novela histórica" y "Metaficción historiográfica" en Historia secreta de Costaguana}

Cuando José Altamirano nos advierte que bien pudiera haber fijado el nacimiento de su padre en la misma fecha en que Bolívar hizo su entrada triunfal a Bogotá, alegando que no habría testigos que pudieran contradecirlo y que, después de todo, él se encuentra en posición de contar la historia de su vida como mejor le parezca, se experimenta lo que pudiéramos llamar el vértigo de la arbitrariedad, la poca confianza que nos sentimos obligados a dispensarle a las palabras del narrador de una novela histórica. Pero ése, más que el riesgo, parece ser el objetivo de los novelistas posmodernos: la puesta en cuestión de la realidad del mundo a través del cuestionamiento de sus representaciones. De hecho, la "ficcionalización", que potencialmente permite subvertir cualquier verdad histórica, se cimienta en la idea -avalada también por la nueva historia- de "la historia como construcción discursiva", como narrativa particular que, con base en hechos registrados como reales, se elabora desde una perspectiva cultural e ideológica concreta (Pons, 1996: 64). Otra forma de decir que, más allá del aparato teórico que los respalda, los

\footnotetext{
${ }^{31}$ Es aquí donde entra a jugar un papel importante la idea de "discurso" como clave para entender la "formación histórica de los conceptos", que "no son meras representaciones o etiquetas de fenómenos ya existentes, sino más bien formas históricamente específicas de hacer inteligible o significativa la propia realidad social" (Cabrera, 2001: 14).

${ }^{32}$ A propósito de estas afirmaciones, Valeria Grinberg Pla destaca lo siguiente: "La idea de que el conocimiento histórico se produce en y por el lenguaje implica sin lugar a dudas una revolución para las concepciones tradicionales de la historia. Es más, probablemente la característica más importante del cambio de paradigma de la historia como ciencia en la segunda mitad del siglo XX consista en definir a la historia como discurso y no como suceder. Esto no significa que se ponga en cuestión la existencia del pasado, sino que expresa la convicción de que el pasado sólo es cognoscible a través del discurso. De ello se deduce que es el relato del pasado el que lo convierte en historia" (2001).
} 
relatos de la historia sólo pueden aspirar a construir una versión de los acontecimientos reales.

Ese proceso de “conceptualización”, mediante el cual los individuos se crean una imagen del mundo, de los otros y de sí mismos en relación con ellos, es el que media entre el historiador y el mundo que trata de explicar. De ahí que sus relatos estén parcializados por efecto de las circunstancias históricas que lo condicionan a él mismo (Cabrera, 2001: 50-2). Esta conciencia de la imposibilidad de retratar fielmente el mundo o, si se quiere, de representarlo sin la intervención de un sujeto parcial que lo asume desde su posición específica, es lo que Pons llama la "discursivización" de la historia ${ }^{33}$. A partir de esta dificultad para interpretar el mundo sin las herramientas discursivas que cada momento histórico le proporciona al sujeto enunciador (al novelista y al historiador, por igual), pudiéramos resumir, con estas palabras de Fernández Prieto, la idea germinal de las exploraciones más osadas que ha llevado a cabo la novela histórica de finales del siglo XX:
Al pasado sólo podemos acceder a través de textos que nos lo cuentan, textos que, a su vez, no son neutros sino que han sido elaborados de acuerdo con unos filtros epistemológicos e ideológicos que seleccionaban de entre lo que sucedía aquello que merecía ser integrado en una narración valorada como histórica. Por lo tanto, no es posible dar cuenta de ninguna realidad, presente o pasada, en estado puro, incontaminada de la perspectiva cultural del observador y ajena a un orden discursivo (1995: 214).

Nos encontramos así frente a una producción novelística que no es ajena de ninguna manera al debate teórico sobre la posmodernidad, y que se constituye en una toma de posición, implícita o explícitamente enunciada, frente a la crisis de las "grandes narrativas" de la era moderna (Pons, 1996: 23). Si consideramos la historicidad de los géneros, debemos apuntar que la novela histórica de fines del siglo XX está fuertemente condicionada por la interpretación que hacen los escritores de las circunstancias históricas suscitadas a raíz de los cambios económicos, políticos y culturales que marcaron este periodo. De igual modo, si nos arriesgamos a proponer una conciencia de época como respaldo de esta nueva escritura de la novela histórica, debemos decir que lo que mejor la refleja es la presencia infaltable de una voz que se hace eco a sí misma, que habla y enseguida denuncia

\footnotetext{
${ }^{33}$ Aquí volvemos a la noción de discurso como aparato lingüístico e ideológico con que cuenta el sujeto para aprehender o elaborar un significado del mundo.
} 
el carácter parcial de cuanto dice. Una especie de objeción en tiempo real, un decir que no ignora que su objeto es impenetrable, ajeno de muchas formas a cuanto de él se dice. Y entre las advertencias más reiteradas están las que señalan el papel que juega la perspectiva en el otorgamiento de sentido. El lugar tan común sobre la verdad y el ojo que la mira.

En el momento en que Joan Oleza Simó cita a F. Jameson (Posmodernism or the Cultural Logic of late Capitalism, 1991) para explicar la vuelta hacia el pasado por parte de los "productores culturales" como una consecuencia directa de "la crisis del Sujeto y del estilo personal" (1995: 82), resulta inevitable preguntarse si podemos iluminar el caso latinoamericano a partir de esa crisis del sujeto occidental y en qué medida la novela histórica producida en América Latina es enteramente latinoamericana. Es decir: ¿cuál es su respuesta a los problemas culturales, económicos y políticos de la región? ¿Acaso podemos afirmar, como Seymour Menton, que el auge de la "nueva novela histórica" durante los años setenta estuvo motivado principalmente por la cercanía del quinto centenario del descubrimiento de América (1993: 48), o debemos decir que dicha revitalización del género histórico fue impulsada por la búsqueda de los cimientos de una identidad colectiva, contraria al impulso individualizador señalado por Bloom en los escritores europeos (Parkinson Zamora, 2004: $24)$ ¿ ¿ es que, según resalta Pons, todo esto es resultado de cambios sociohistóricos mucho más complejos y profundos como "la desazón frente al fracaso de la gesta libertadora de los años cincuenta y sesenta" (Pons, 1996: 21)?

Cada una de estas premisas es válida en la medida en que se les puede aplicar a ciertos casos particulares ${ }^{34}$, pero deja de serlo en cuanto es asumida como explicación generalizadora. Incluso podríamos decir que, más allá de esta encrucijada en que se ha convertido la "crisis de la modernidad", agravada por lo crítica que ha sido siempre la modernidad latinoamericana, muchas delas novelas históricas obvian los problemas culturales de fondo y hasta se justifican únicamente por necesidades de rotación editorial. De todos modos, lo que sí podemos identificar claramente son las principales características de la novela histórica de finales del siglo XX y principios del XXI, que nos permiten diferenciarla de las novelas históricas producidas en otros periodos. Como Lukács al momento de proponer en Waverley (1814) el primer precedente de novela histórica plenamente configurada

${ }^{34}$ William Ospina, por ejemplo, reconoce que su trilogía sobre la conquistada de América estuvo inspirada, inicialmente, por "la conmemoración del quinto centenario del llamado Encuentro de los Mundos" (Ospina, 2009: 2). 
(1976: 15), Menton arriesga la proposición de considerar El reino de este mundo (1949), de Alejo Carpentier, como la primera "nueva novela histórica" latinoamericana (1993: 38).

Publicada en 1949, esta novela reúne -muchos de ellos en estado germinal- los lineamientos escriturales más notorios del tipo de novela histórica que, según Menton, habría de transformar el canon, a saber: 1) En vez de reproducir miméticamente el pasado, se empeña en desarrollar algunas "ideas filosóficas" relacionadas con "la imposibilidad de conocer la verdad histórica o la realidad", "el carácter cíclico de la historia" y, paradójicamente, su "carácter imprevisible"; 2) distorsiona la historia "a través de omisiones, exageraciones y anacronismos"; 3) ficcionaliza personajes históricos, a diferencia de la fórmula de Walter Scott de sólo permitir protagonistas ficticios; 4) la narración está constantemente cortada por marcas "metaficcionales" o comentarios del narrador sobre el proceso de creación; 5) "El concepto de intertextualidad reemplaza aquel de entresubjetividad [sic], y el lenguaje poético tiene por lo menos dos maneras de leerse"; las alusiones a otras obras, "a menudo explícitas, se hacen frecuentemente en tono de burla"; y por último, 6) es una novela histórica que muestra un carácter marcado por lo dialógico ("proyecta dos o más interpretaciones de los sucesos, los personajes y la visión de mundo") y lo carnavalesco (la presencia constante de la parodia y las exageraciones humorísticas); y la heteroglosia ("la multiplicidad de discursos") se constituye en una de sus formas predilectas de presentar la historia (Menton, 1993: 42-45).

Tal como La novela histórica de Lukács, el ensayo de Menton sobre la "nueva novela histórica latinoamericana" ha venido a constituirse también en un punto de referencia obligado, ya sea para ampliar las miras en la consideración de este fenómeno literario como para contradecir sus principales planteamientos. En este último caso se halla Lukasz Grützmacher, profesor de la Universidad de Varsovia. En un artículo titulado "Las trampas del concepto 'la nueva novela histórica' y de la retórica de la historia postoficial" (2006), Grützmacher advierte sobre la necesidad de reevaluar los términos en que están siendo estudiadas las novelas históricas de corte posmoderno. Para ello empieza denunciando la falsa novedad de las atribuciones con que Menton pretende caracterizar las por él llamadas "nuevas novelas históricas". Según Grützmacher, ya Lukács había demostrado "el impacto que ideas filosóficas como 'la incognoscibilidad del curso de la historia en sí,, 'la libre y arbitraria interpretabilidad de los hechos' o 'la necesidad de la 'introyección' de los propios problemas subjetivos en la historia amorfa'", tuvieron en las novelas históricas en el siglo XIX (2006: 144). En esta misma lista, 
enumera también "el 'florecimiento del jugueteo formal decadente' y 'una consciente violación de la historia'" (146). Por otra parte, nos dice el profesor polaco, "la intertextualidad no es un rasgo distintivo, puesto que toda novela histórica es intertextual por excelencia", y "la dimensión dialógica la podemos encontrar en todo discurso, también en la novela histórica 'tradicional' que, en la mayoría de los casos, polemiza con otros textos (sobre todo con la llamada 'historiografía oficial')" (Ibíd.).

Queda claro que lo que intenta Grützmacher es demostrar que el concepto de "nueva novela histórica" no es el más apropiado para nombrar el fenómeno literario que ha tenido lugar, sobre todo en América Latina, a finales del siglo XX, en oposición a lo que el propio Menton llama "novela histórica tradicional". La propuesta teórica de Menton sólo se justificaría en tanto refleja una corriente global: "Es decir, puesto que cada vez más autores se dirigen hacia el polo postmoderno, podríamos hablar de una 'nueva' novela histórica, entendida como tendencia" (2006: 150). La novedad de esas novelas no consiste, entonces, en el uso de nuevos recursos -no es una novedad de lo nuevo- sino en una utilización insospechada de los recursos viejos. De ahí que, por ser las marcas metatextuales uno de los recursos de representación más explotados entre los nuevos novelistas, Grützmacher proponga como más "preciso y coherente" el uso del término "metaficción historiográfica", acuñado por Linda Hutcheon en su libro A Poetics of Postmodernism: History, Theory, Fiction (1988):

En el planteamiento de Hutcheon es esencial la distinción entre los acontecimientos acaecidos y los hechos históricos. Los acontecimientos realmente tuvieron lugar en algún momento, pero no nos son accesibles; disponemos tan sólo de relaciones posteriores sobre estos acontecimientos, de los hechos que tienen carácter narrativo y son construidos por el que hace la relación, sea un escritor, sea un historiador. En otras palabras, no existe una diferencia fundamental entre la creación de los hechos ficticios en una obra literaria y la construcción de los llamados hechos "históricos" en un texto historiográfico. Las metaficciones historiográficas no sólo, como toda narración, construyen unos hechos, sino que enseguida los cuestionan y muestran su carácter subjetivo y provisional. Hutcheon opina que el proceso de transformación del conocimiento (los acontecimientos) en narración (los hechos) se ha convertido en la obsesión de la literatura postmoderna que se concentra en denunciar la naturaleza lingüística de los hechos (Grützmacher, 2006: 150-151). 
La principal característica de las novelas que Hutcheon inscribe dentro de esta categoría es la poca inocencia que muestran frente a "la naturaleza discursiva e intertextual del pasado y su carácter paradójico, pues su estructura se establece sobre contenidos opuestos de imposible reconciliación” (Fernández Prieto, 1995: 251). Una autoconciencia de la relatividad del conocimiento histórico, que les permite distorsionar el pasado a través de la parodia y la manipulación de los relatos de la historia. Como corolario de lo dicho hasta ahora, cabe resaltar que un acercamiento a Historia secreta de Costaguana nos aboca, en primer lugar, al análisis de un narrador que presume siempre de ser dueño absoluto de su propia historia, y que funda en ello su potestad para manipular los sucesos históricos según su propia conveniencia. En segundo lugar, a la consideración de las relaciones entre literatura e historia: un continuo juego intertextual que permite adelantar múltiples lecturas sobre unos mismos acontecimientos y abrir, desde la ficción, nuevas posibilidades de conocer el pasado.

\section{Bibliografía}

Aguirre, M. (2001). El Romanticismo: de Rousseau a Víctor Hugo. La Habana: Editorial Pueblo y Educación.

Barthes, R. (2005). El grado cero de la escritura. México: Siglo XXI Editores. Borges, J. L. (2007). Obras Completas. Bogotá: Planeta, Vol. II.

Cabrera, M. A. (2001). Historia, lenguaje y teoría de la sociedad. Madrid: Ediciones Cátedra (Grupo Anaya S. A.).

Carpio Franco, R. (2009). Espejos, simulacros y distorsiones: hacia una tipología de la metaficción historiográfica en Historia secreta de Costaguana de Juan Gabriel Vásquez. Trabajo de Grado. Facultad de Ciencias Humanas. Programa de Lingüística y Literatura, Universidad de Cartagena, $114 \mathrm{p}$.

Conrad, J. (2005). Nostromo. Barcelona: Laertes. (2008). Crónica personal. Barcelona: Random House Mondadori.

Curcio Altamar, A. (1957). Evolución de la novela en Colombia. Bogotá: Instituto Caro y Cuervo.

Deas, M. (2006). Del poder y la gramática y otros ensayos sobre historia, política y literatura colombianas. Bogotá: Taurus.

Escobar Mesa, A. (2003). "La novela histórica: una contradicción realizada", Memorias del XIX Coloquio Internacional de Literatura Mexicana e Hispanoamericana. Hermosillo: Universidad de Sonora, Departamento de Letras y Lingüística.

Espinosa, G. (2002). Ensayos completos, 1968-1988. Medellín: Fondo Editorial EAFIT, Vol. I.

Fernández Prieto, C. (1996). "Poética de la novela histórica como género literario", Signa: revista de la Asociación Española de Semiótica, $\mathrm{n}^{\circ}$. 5, Madrid: Centro de Investigación de Semiótica Literaria, Teatral 
y Nuevas Tecnologías, Departamentos de Literatura Española y Teoría de la Literatura y Filología Francesa, Universidad Nacional de Educación a Distancia. (1995). "Relaciones pasado-presente en la narrativa histórica contemporánea”. En Romera Castillo, José, et al. (Eds.). La novela histórica a finales del siglo XX (Actas del V Seminario Internacional del Instituto de Semiótica y Teatral de la UNED). Madrid: Visor.

Franco, J. (1990). Historia de la literatura hispanoamericana, $8^{\mathrm{a}}$ Ed. Barcelona: Ariel.

Friera, Silvina. (2009). "La novela sirve para contarnos de dónde venimos" en http//www.desdeabajo.info/index.php/actualidad/colombia/3102entrevista-al-colombiano-juan-gabriel-vasquez-la-novela-sirvepara-contarnos-de-donde-venimos.html).

García Márquez, G. (1985) El amor en los tiempos del cólera. Bogotá: La Oveja Negra.

Genette, G. (1989). Palimpsestos. Madrid: Taurus.

Grinberg Pla, V. (2001). "La novela histórica de finales del siglo XX y las nuevas corrientes historiográficas", Istmo, $n^{\circ} 2$.

Grützmacher, L. (2006). "Las trampas del concepto "la nueva novela histórica” y de la retórica de la historia postoficial”, Acta poética, no. 27, México, UNAM, pp. 141-167.

Jitrik, N. (1995). Historia e imaginación literaria: las posibilidades de un género. Buenos Aires: Editorial Biblos.

Lukács, G. (1976). La novela histórica. Barcelona: Grijalbo.

McGrady, D. (1960). La novela histórica en Colombia, 1844-1959. Bogotá: Editorial Kelly.

Melo, J. O. (1998). "La literatura histórica en la República". En Manual de literatura colombiana. Bogotá: Planeta.

Menton, S. (1993). La nueva novela histórica en la América Latina, 1979-1992. México: Fondo de Cultura Económica.

Oleza Simó, J. (1995). "Una nueva alianza entre historia y novela. Historia y ficción en el pensamiento literario de fin de siglo". En Romera Castillo, José, et al. (Eds.). (1996). La novela histórica a finales del siglo XX (Actas del V Seminario Internacional del Instituto de Semiótica y Teatral de la UNED), Cuenca: VIMP, (3 a 6 de julio), Madrid: Visor.

Ospina, William. (2009). "Elogio de las causas" (Discurso leído al recibir el Premio de Novela Rómulo Gallegos). El espectador (Bogotá), 3 de agosto.

Parkinson Zamora, L. (2004). La construcción del pasado: la imaginación histórica en la literatura americana reciente. México. Fondo de Cultura Económica.

Pons, M. C. (1996). Memorias del olvido: la novela histórica de fines del siglo $X X$. México: Siglo XXI Editores.

Pulido Herráez, B. (2006). Poética de la novela histórica contemporánea. México: UNAM. 
Rey Pereira, C. (2000). Discurso histórico y discurso literario: el caso de El Carnero. Tesis de Doctorado en Filosofía y Letras. Universidad Autónoma de Madrid, Madrid.

Subirats, E. (2001). "El amanecer de los ídolos”. En Culturas virtuales. México: Ediciones Coyoacán, pp. 75-83.

Vásquez, J. G. (2004). Los informantes. Bogotá: Alfaguara. . (2007a) "El arte de la distorsión", El Malpensante, $n^{\circ}$ 76, Bogotá.

. (2007b). Historia secreta de Costaguana. Bogotá: Alfaguara.

. (2007c). Joseph Conrad: el hombre de ninguna parte. Bogotá: Panamericana Editorial.

Volpi, J. (2009a). "Después de Bolaño, no hay literatura latinoamericana", El periódico de México, México, 21 de septiembre, en: http://www. elperiodicodemexico.com /nota.php?id=293655).

. (2009b)." "No hay una literatura latinoamericana'”, El Tiempo, Bogotá, 29 de agosto.

White, H. (1992). El contenido de la forma. Narrativa, discurso y representación histórica. Barcelona: Paidós. 
